\section{- is enabling Singapore's move toward an innovation-based economy}

Materials research support of a wide range of scientific and engineering activity.'

Because A*STAR falls under the MTI, its charge is to conduct research that will attract and grow industry and thereby enhance Singapore's economy. Its marketing and commercialization arm, Exploit Technologies, encourages licensing, supports the formation of start-ups, and helps forge partnerships with companies. One recent spin-off company, Tera-Barrier Films, grew out of work done at IMRE on moisture-resistant barriers for plastic electronics.

The goal of licensing and collaborating with industry is not primarily to support research at A*STAR. "We view those consortia as a way of taking technology and expertise developed here and sharing those with industry," Srolovitz said. "A*STAR's research institutes have mechanisms to encourage our staff to go out and spend a year or two at a company to share our domain expertise and then return to our research institutes. Some of our staff end up remaining at these companies. We also view this as one of our important contributions to the development of the Singapore economy." Singapore gets significant leverage out of this approach; every dollar put in by the government attracts twice that from the private sector.

Faculty at Singapore's two research universities, Nanyang Technological University (NTU) and the National University of Singapore (NUS), get a mix of funding from industry, A*STAR, and the for Science, Technology, and Research (A*STAR) opened the first phase of Fusionopolis, a hub for information sciences, physical sciences, and engineering. The second phase, now under construction, will feature state-of-the-art clean rooms, a nanofabrication and characterization facility, and a high-performance computing center.

Singapore's small size has forced it to be strategic in allocating funds to research areas where it is most likely to make an impact. R\&D funding is allocated over five-year periods and channeled through three entities. The National Research Foundation (NRF) funds new initiatives and programs to develop new growth areas and capabilities. The Ministry of Education distributes grants for technology, the Institute of Microelectronics, and the Data Storage Institute.

"In addition to bringing new technologies to society, the largest contribution of materials science is as an enabler of new technologiesin almost every realm of engineering and invention," said David Srolovitz, scientific advisor for A*STAR's Science and Engineering Research Council and executive director of the Institute for High Performance Computing (MRS Fellow). "As a result, we see IMREand materials science in Singapore more broadly - both as a developer of new technology and in

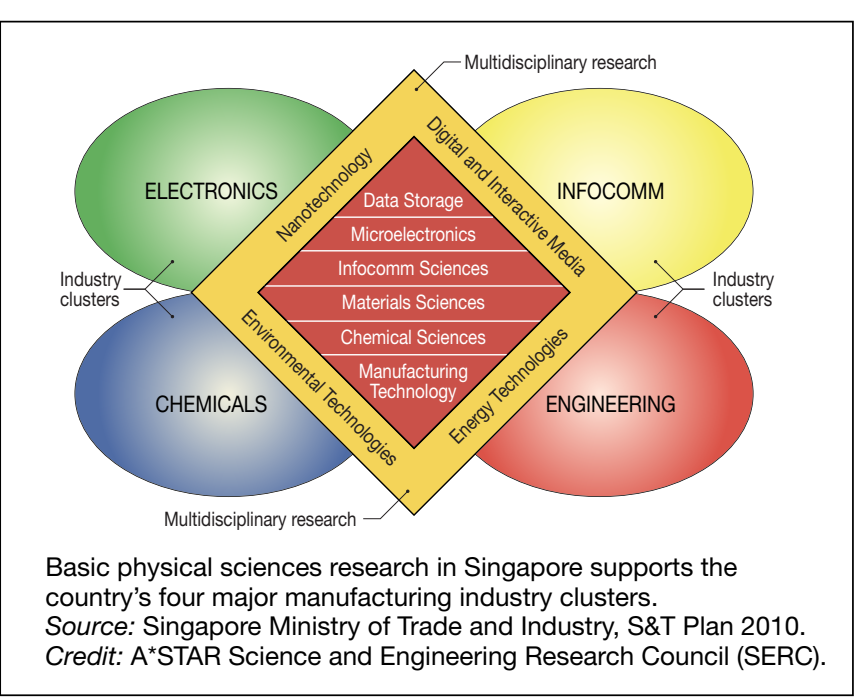


government agencies. They are encouraged to commercialize their technology, but it's not yet the main goal of most professors, said Gan Moog Chow, head of the materials science and engineering department at NUS. Still, the research is "application-inspired discovery of cutting-edge knowledge with timely Asian and global relevance," he said. Because funding follows a roadmap outlined by Singapore's government, there's always an economic reason for the research, said Freddy Boey, chair of NTU's school of materials science and engineering. "We are a small country. We cannot afford to do really blue-sky research, but we do enough to attract the best brains in the world to come for economic value."

Indeed, Singapore prides itself on the international character of its scientific community. More than a third of its researchers with $\mathrm{PhD}$ degrees - and a quarter of the residents overall — are from somewhere else. Singapore's stable government, modern living standards, and English-speaking population make for a relatively easy adjustment. After working in R\&D at Canon Research Center Americas, Alan Sellinger spent five years as a senior scientist at IMRE researching organic light-emitting diodes, solar cells, and teaching at NTU.
"As a place to go and experience from a professional standpoint, it was great," Sellinger said. He published articles and met researchers from all over the world. Sellinger returned to the United States in 2008 to become a consulting professor in Stanford University's materials science and engineering department and executive director of the Center for Advanced Molecular Photovoltaics.

A*STAR hires more than $200 \mathrm{PhD}$ level scientists each year, and about a quarter of them would likely work on materials-related research, so job opportunities abound.

Corinna Wu
Europe invests $€ 6.4$ billion in research and innovation http://cordis.europa.eu/fp7/dc/index.cfm

C ommissioner Máire GeogheganQuinn has announced in July nearly $€ 6.4$ billion of European Commission investment in research and innovation. The package covers a vast range of scientific disciplines, public policy areas, and commercial sectors. This funding is expected to advance scientific boundaries, increase European competitiveness, and to help solve societal challenges such as climate change, energy and food security, health, and an aging population.

Around 16,000 participants from research organizations, universities, and industry, including about 3,000 small and medium-sized enterprises (SMEs), will receive funding. Grants will be awarded through "calls for proposals" and evaluations over the next several months. Many calls have been formally published on July 20th.

Within the 7th Framework Program, within Information and Communication Technologies (ICT) are calls for "Factories of the Future 2011," including research in Theme 4 on Nanosciences, Nanotechnologies, Materials, and New Production Technologies, and also "ICT for Green Cars 2011"; several calls for proposals in energy, including specific cooperation between researchers in the European Union (EU) and Japan; and a call for proposals in electrochemical storage, crossing the Theme programs of Environment, Transportation, and Nanosciences, Nanotechnologies, Materials, and New Production Technologies.

According to the commissioner, this package is an economic stimulus expected to create more than 165,000 jobs. It is also a long-term investment in a smarter, sustainable, and a more inclusive Europe. It is a key element within the EU's Europe 2020 Strategy and in particular the Innovation Union Flagship, which will be launched in autumn 2010. The $€ 1.2$ billion boost to Information and Communication Technology (ICT) research, will help deliver the European Commission's (EC) commitment in the "Digital Agenda for Europe" initiative to maintain the pace of yearly increases in ICT funding.

More than $€ 1.3$ billion are reserved for the best creative scientists selected by the European Research Council. Mobility grants for 7,000 highly qualified researchers will be provided through "Marie Curie Actions," worth €772 million.

According to the commissioner, top priority is given to SMEs, the backbone of the European innovation system, representing $99 \%$ of all European businesses. SMEs will receive close to $€ 800$ million and in the areas of health, knowl- edge-based bio-economy, environment, and nanotechnologies, SME participation must reach $35 \%$ of the total budget for a number of topics.

Translating research into new technologies, products, and services is at the heart of the package. In nanotechnologies (€270 million), for example, the focus will be on research that could lead to patenting and commercialization opportunities.

Around $€ 600$ million of ICT funding is earmarked for next-generation network and service infrastructures, robotic systems, electronic and photonic components, and digital content technologies. More than $€ 400$ million will support research into how ICTs can address challenges such as a lower-carbon economy, an aging society, and adaptable and sustainable factories.

Environment research projects will receive about $€ 205$ million. This year, the Commission is introducing steps to speed up sharing of environmental research results: beneficiaries of EU grants will commit to making freely available - after a certain embargo period-publications arising from their research.

The budget for the 7th Framework Program calls for proposals in 2011 is $€ 6.4$ billion, up $12 \%$ in comparison to 2010 ( $€ 5.7$ billion) and 30\% in comparison to 2009 (€4.9 billion). 